CLINICAL STUDY

\title{
Association of genetic variants in the adiponectin gene with adiponectin level and hypertension in Hong Kong Chinese
}

\author{
Kwok Leung Ong ${ }^{1, *}$, Mingfang $\mathrm{Li}^{1, *}$, Annette W K Tso ${ }^{1,2}$, Aimin $\mathrm{Xu}^{1,2}$, Stacey S Cherny ${ }^{3,4}$, Pak Chung Sham ${ }^{3,4,5}$, \\ Hung Fat Tse ${ }^{1}$, Tai Hing Lam ${ }^{6}$, Bernard M Y Cheung ${ }^{1,2}$, Karen S L Lam ${ }^{1,2}$ and on behalf of the Investigators of the \\ Hong Kong Cardiovascular Risk Factor Prevalence Study \\ ${ }^{1}$ Department of Medicine, ${ }^{2}$ Research Centre of Heart, Brain, Hormone and Healthy Aging, ${ }^{3}$ Department of Psychiatry, ${ }^{4}$ The State Key Laboratory of Brain \\ and Cognitive Sciences, ${ }^{5}$ Genome Research Centre and ${ }^{6}$ Department of Community Medicine, University of Hong Kong, Hong Kong, Hong Kong \\ (Correspondence should be addressed to K S L Lam who is now at University Department of Medicine, Queen Mary Hospital, Hong Kong, Hong Kong; \\ Email: ksllam@hku.hk; B M Y Cheung who is now at University Department of Medicine, Queen Mary Hospital, Hong Kong, Hong Kong; \\ Email: mycheung@hku.hk) \\ *(K L Ong and M Li contributed equally to this work)
}

\begin{abstract}
Objective: Low plasma adiponectin level can predict the development of hypertension after 5 years in our population. We therefore investigated whether single-nucleotide polymorphisms (SNPs) in the adiponectin gene influenced plasma adiponectin level and whether they were associated with hypertension.

Design and methods: We genotyped 14 tagging SNPs in 1616 subjects with persistent normotensive or hypertensive status during a 6.4-year follow-up period in the Hong Kong Cardiovascular Risk Factor Prevalence Study-2 (CRISPS-2). Plasma adiponectin level was measured in 1385 subjects using in-house sandwich ELISA.

Results: The minor G allele of the SNP rs266729 was significantly associated with higher odds of hypertension (odds ratio $(95 \%$ confidence interval $)=1.49(1.13-1.95), P=0.0044)$ after adjusting for covariates. In stepwise multiple logistic regression, this SNP $(P=0.006)$ was a significant independent factor of hypertension, together with age $(P<0.001)$, body mass index $(P<0.001)$, triglycerides $(P=0.021)$, and insulin resistance index $(P<0.001)$. Among the 14 SNPs, rs $266729(\beta=-0.067$, $P=0.0037), \quad-10677 \mathrm{C}>\mathrm{T}(\beta=0.069, P=0.0027)$, rs182052 $(\beta=-0.097, P<0.0001)$, and rs12495941 $(\beta=0.103, P<0.0001)$ were significantly associated with adiponectin level after adjusting for covariates. No significant sex interaction was found for the associations of SNPs with hypertension and adiponectin level. Similar results were obtained in haplotype analysis. Conclusion: In our population, genetic variants in the adiponectin gene influenced plasma adiponectin levels, and one of them was associated with hypertension. This study has provided further evidence for a role of adiponectin in the development of hypertension.
\end{abstract}

European Journal of Endocrinology 163 251-257

\section{Introduction}

Adipose tissue has recently been recognized as an endocrine organ. One of its secretory products is adiponectin, which has been shown to increase insulin sensitivity via promotion of lipid $\beta$-oxidation in skeletal muscles and reducing hepatic gluconeogenesis $(1,2)$. It has direct vasoprotective actions such as stimulation of prostaglandin $\mathrm{I}_{2}$ synthase and endothelial nitric oxide synthase activity (3). A low circulating level of adiponectin is associated with endothelial dysfunction, diabetes, obesity, inflammation, and coronary artery disease $(1,4)$.

Hypoadiponectinemia is associated with hypertension in cross-sectional case-control studies $(5,6)$.
We and others have previously reported that low adiponectin level is predictive of the development of hypertension in prospective studies $(7,8)$. Genetic factor accounts for about $40-70 \%$ of the variation in adiponectin levels (9). Genetic variants in the gene encoding adiponectin $(A D I P O Q)$ have been reported to be associated with adiponectin level in several genomewide linkage and association studies (9-11). However, inconsistent findings on the association of genetic variants of $A D I P O Q$ with adiponectin level (9-13) and hypertension $(5,6,14)$ have been reported, which could be due to a difference in ethnic populations, singlenucleotide polymorphism (SNP) selection, and study power. To our best knowledge, there was no systematic analysis of SNPs in ADIPOQ gene with regard to both 
adiponectin level and hypertension in Chinese population. As female gender is well known to be associated with higher adiponectin level (15), it is worthwhile to investigate whether there is any interaction between sex and genetic variants on adiponectin level and risk of hypertension.

In this study, we investigated the association of common genetic variants in the ADIPOQ gene with adiponectin level and hypertension. We included subjects with persistent normotensive or hypertensive status during a 6.4-year follow-up period in the population-based Hong Kong Cardiovascular Risk Factor Prevalence Study-2 (CRISPS-2).

\section{Subjects and methods}

\section{Subjects}

The Hong Kong CRISPS was a cohort study of cardiovascular risk factors in the Hong Kong Chinese $(16,17)$. Of the 2895 subjects who initially participated (CRISPS-1), 1944 enrolled in the follow-up study (CRISPS-2) in 2000-2004 after a median interval of 6.4 years. The study protocol was approved by the ethics committee of the University of Hong Kong. All subjects gave written consent. In this study, we included all the 285 hypertensive subjects and 1331 normotensive subjects with DNA samples available who were either hypertensive or normotensive at baseline and also at the 6.4-year follow-up assessment. As plasma samples were not available for the majority of subjects at baseline, adiponectin level was measured only in plasma samples at follow-up $(n=1385)$, and thus, data at the follow-up were used in all the analyses. There was no significant difference in age, sex, body mass index (BMI), and hypertension prevalence between subjects with and without measurement of adiponectin level (all $P>0.05$ ).

\section{SNPs selection and genotyping}

Tagging SNPs were selected in the ADIPOQ gene from the HapMap Han Chinese population (Phase II data, release 22). There were 13 tagging SNPs (rs16861194, rs266729, rs182052, rs16861205, rs822396, rs12495941, rs7649121, rs7627128, rs1501299, rs3774262, rs6773957, rs1063539, and rs12629945), which captured all the 21 SNPs from 5 -kb region upstream to $2-\mathrm{kb}$ downstream of the gene (position 188,038,157-188,060,946, GenBank accession number NC_000003, NCBI build 36) with $r^{2} \geq 0.9$ and minor allele frequency (MAF) $\geq 0.05$. However, genotyping was not performed for the SNP rs7627128 as it could not be incorporated into Sequenom multiplex assay. This SNP showed a $r^{2}$ of 0.85 with rs7649121 and a $r^{2}$ of 0.53 with $\mathrm{rs} 266729$. In addition, three SNPs (rs822395, rs2241766, and
$-10677 \mathrm{C}>\mathrm{T}$ ) identified in our previous study (18), but not in the HapMap project, were also genotyped in this study. Genotyping was performed using the MassARRAY system (Sequenom, San Diego, CA, USA) with the iPLEX assay in the Genome Research Centre, University of Hong Kong.

\section{Phenotypes and other variables of interest}

Hypertension was defined as blood pressure $\geq 140 / 90 \mathrm{mmHg}$ or on anti-hypertensive medication. Pulse pressure was defined as the difference between systolic and diastolic blood pressure. Mean arterial pressure (MAP) was calculated as the sum of diastolic blood pressure and one-third of the pulse pressure. Blood pressure was measured as described previously $(16,17)$. Circulating total adiponectin level was measured with an in-house sandwich ELISA established in our laboratory (intra-assay and inter-assay coefficients of variation of $6.2-8.3$ and $5.1-6.4 \%$ respectively) (19). Plasma high-sensitivity C-reactive protein (hsCRP) was measured as described previously $(20,21)$. Drinking was defined as consumption of alcoholic drinks at least once a week. Regular exercise was defined as having exercise for $\geq 30 \mathrm{~min}$ at least once a week in the past month. Smoking was defined as ever smoking in their lives. Other clinical parameters such as glucose, insulin, and lipid profile were measured as described previously $(16,17)$.

\section{Statistical analysis}

Haploview version 4.1 was used to assess linkage disequilibrium (LD) (22). Analysis of SNPs and haplotypes was performed using program PLINK (version 1.0.6) (23). Variables with skewed distributions were ln-transformed before analysis. Multivariate logistic or linear regression models were used to estimate the odds ratios (OR) or regression coefficients under the assumption of an additive effect of allele dosage. Correction for multiple testing was performed by the SNP spectral decomposition method (SNPSpD) (24). Under this method, the effective number of independent marker loci $\left(\mathrm{M}_{\text {effLi }}\right)$ was 9, and the experimental-wide significance threshold to keep type 1 error rate at $5 \%$ was 0.0057. Correction for testing of multiple phenotypes was not performed as the phenotypes tested were closely related to each other. The $P$ values for interaction were estimated by including the multiplicative interaction term in the multivariate regression models in full sample after adjusting for the main effects of all covariates.

In PLINK, haplotypes were inferred using the expectation-maximization algorithm. For haplotype analysis, only haplotypes with frequency $>0.05$ were tested. An omnibus test was performed to assess the global $P$ value of the overall variation at the locus. 


\section{Results}

\section{Subject characteristics and genotyping}

Table 1 shows the characteristics of the 1616 subjects in the subcohort who were persistently hypertensive $(n=285)$ or normotensive $(n=1331)$ during the 6.4-year follow-up period. As expected, hypertensive subjects had worse cardiovascular risk profile and lower adiponectin level $(P<0.001)$ than the normotensive subjects.

Among the 15 SNPs genotyped, only the SNP rs7649121 showed significant deviation from HardyWeinberg equilibrium $(P<0.0001$ among all subjects or among case- and control-specific subgroups), and was excluded from subsequent analysis. This SNP also showed significant deviation from Hardy-Weinberg equilibrium in the HapMap Han Chinese population $(P=0.0056)$. The genotyping rates of the remaining 14 SNPs were all $\geq 99.2 \%$. There were five SNP pairs showing high pairwise LD pattern (SNPs 1 and 5, SNPs 6 and 7, SNPs 9 and 11, SNPs 9 and 13, and SNPs 11 and 13; all $\left.r^{2}>0.80\right)$.

Table 1 Clinical characteristics of the 1616 subjects at the follow-up. Data are expressed as mean \pm s.D. or geometric mean (95\% confidence interval) unless otherwise stated.

\begin{tabular}{|c|c|c|}
\hline & $\begin{array}{l}\text { Normotensive } \\
(n=1331)\end{array}$ & $\begin{array}{l}\text { Hypertensive } \\
(n=285)\end{array}$ \\
\hline Age (years) & $48.8 \pm 10.5$ & $63.2 \pm 9.9^{\dagger}$ \\
\hline Women (\%) & 56.0 & 50.9 \\
\hline BMI $\left(\mathrm{kg} / \mathrm{m}^{2}\right)$ & $23.5 \pm 3.3$ & $26.5 \pm 3.9^{\dagger}$ \\
\hline Waist circumference $(\mathrm{cm})$ & $78.0 \pm 9.4$ & $85.9 \pm 10.0^{\dagger}$ \\
\hline $\begin{array}{l}\text { Systolic blood pressure } \\
(\mathrm{mmHg})^{\mathrm{a}}\end{array}$ & $113.9 \pm 11.3$ & $153.9 \pm 14.3^{\dagger}$ \\
\hline $\begin{array}{l}\text { Diastolic blood pressure } \\
(\mathrm{mmHg})^{\mathrm{a}}\end{array}$ & $72.1 \pm 8.2$ & $86.3 \pm 12.7^{\dagger}$ \\
\hline Pulse pressure $(\mathrm{mmHg})^{\mathrm{a}}$ & $41.8 \pm 9.0$ & $67.6 \pm 15.8^{\dagger}$ \\
\hline $\operatorname{MAP}(\mathrm{mmHg})^{\mathrm{a}}$ & $86.0 \pm 8.3$ & $108.9 \pm 11.0^{\dagger}$ \\
\hline Triglycerides (mmol/l) & $1.09(1.07-1.12)$ & $1.49(1.41-1.58)^{\dagger}$ \\
\hline HDL cholesterol $(\mathrm{mmol} / \mathrm{l})$ & $1.37 \pm 0.37$ & $1.24 \pm 0.34^{\dagger}$ \\
\hline LDL cholesterol (mmol/l) & $3.24 \pm 0.80$ & $3.54 \pm 0.90^{\star}$ \\
\hline Fasting glucose (mmol/l) & $5.14(5.09-5.18)$ & $5.90(5.74-6.05)^{\dagger}$ \\
\hline $\begin{array}{l}\text { 2-h post-OGTT glucose } \\
(\mathrm{mmol} / \mathrm{l})\end{array}$ & $6.55(6.43-6.67)$ & $8.38(7.99-8.78)^{\dagger}$ \\
\hline Fasting insulin (mIU/l) & $6.91(6.72-7.10)$ & $10.10(9.41-10.84)^{\dagger}$ \\
\hline HOMA-IR & $1.58(1.53-1.63)$ & $2.65(2.44-2.87)^{\dagger}$ \\
\hline \multirow{2}{*}{\multicolumn{3}{|c|}{ Adiponectin $(\mathrm{mg} / \mathrm{l})^{\mathrm{b}}$}} \\
\hline & & \\
\hline Men & $5.63(5.34-5.94)$ & $5.26(4.71-5.87)^{\dagger}$ \\
\hline Women & $7.91(7.56-8.28)$ & $7.11(6.44-7.86)^{\dagger}$ \\
\hline Smoking (\%) & 29.8 & 31.6 \\
\hline Drinking (\%) & 9.8 & 9.2 \\
\hline Regular exercise (\%) & 29.2 & 44.3 \\
\hline $\begin{array}{l}\text { Anti-hypertensive } \\
\text { medication (\%) }\end{array}$ & - & 79.3 \\
\hline
\end{tabular}

${ }^{\star} P<0.05$ and ${ }^{\dagger} P<0.001$ for normotensive versus hypertensive subjects after adjusting for age and sex, where appropriate.

${ }^{a}$ Subjects on anti-hypertensive medication were excluded $(n=226)$.

${ }^{b}$ Data were available in 1145 normotensive (514 men and 631 women) and 240 hypertensive (120 men and 120 women) subjects.

\section{Hypertension}

Among the 14 SNPs, the minor allele of SNP 2 was significantly associated with higher odds of hypertension after adjusting for age and sex, and correction for multiple testing ( $P=0.0044$; Table 2$)$. The association remained significant after further adjusting for BMI, triglycerides, high-density lipoprotein (HDL) cholesterol, homeostasis model assessment of insulin resistance index (HOMA-IR), and 2-h post-oral glucose tolerance test (OGTT) glucose (OR $(95 \%$ confidence interval $(\mathrm{CI})=1.49(1.13-1.95), P=0.0044)$. In a separate analysis, similar results were obtained under the assumption of dominant allelic effect $(P=0.0024$ in full adjustment model). None of the SNP showed significant sex interaction $(P>0.05)$. In forward stepwise multiple logistic regression, this SNP was a significant independent factor of hypertension (Table 3).

The minor allele of SNP 2 was associated with higher percentage of taking anti-hypertensive medication (12.2, 16.1, and $17.3 \%$ for subjects with CC, CG, and GG genotypes respectively, $P=0.004$ ), and no significant association was found with other clinical characteristics (data not shown). To examine the relationship between SNP 2 genotype and blood pressure traits, we adjusted the blood pressure values in subjects on anti-hypertensive medication by adding 10 and $5 \mathrm{mmHg}$ to systolic and diastolic blood pressures respectively (25). Using this method, the minor allele of SNP 2 was associated with higher diastolic blood pressure after adjusting for age, sex, BMI, triglycerides, HDL cholesterol, HOMA-IR, and 2-h post-OGTT glucose $(\beta=0.053, P=0.019)$. The diastolic blood pressures (mean \pm s.D.) was $74.4 \pm 10.2,75.2 \pm 11.0$, and $75.7 \pm 10.7 \mathrm{mmHg}$ in subjects with CC, CG, and GG genotypes respectively. There was no significant sex interaction $(P$ for interaction $=0.669)$.

\section{Plasma adiponectin level}

Among the 1385 subjects with adiponectin level measured, the level was negatively correlated with BMI, waist circumference, blood pressure, MAP, triglycerides, low-density lipoprotein cholesterol, fasting glucose, 2-h post-OGTT glucose, fasting insulin, HOMA-IR, and hsCRP, and positively correlated with age and HDL cholesterol (all $P<0.05$ after adjusting for age and sex, where appropriate). The level was significantly higher in women $(P<0.001)$, and was not related to drinking, smoking, and regular exercise $(P>0.05)$. Among hypertensive subjects, the level was significantly lower in subjects with anti-hypertensive medication treatment than those without (geometric mean $(95 \% \quad C I)=5.78 \quad(5.34-6.26)$ and 7.83 $(6.35-9.66) \mathrm{mg} / \mathrm{l}$ respectively, $P<0.001$ after adjusting for age and sex). In forward stepwise multiple linear regression, female gender, higher age, lower BMI, lower triglycerides, higher HDL cholesterol, lower 
Table 2 Associations of single-nucleotide polymorphisms (SNPs) with hypertension.

\begin{tabular}{|c|c|c|c|c|c|c|}
\hline \multirow[b]{2}{*}{ No. } & \multirow[b]{2}{*}{ SNP } & \multirow{2}{*}{$\begin{array}{l}\text { Alleles } \\
\text { (major:minor) }\end{array}$} & \multicolumn{2}{|c|}{ MAF } & \multirow[b]{2}{*}{ OR $(95 \% \mathrm{Cl})$} & \multirow[b]{2}{*}{$\boldsymbol{P}$} \\
\hline & & & NT & $\mathrm{HT}$ & & \\
\hline 1 & rs16861194 & $A: G$ & 0.168 & 0.147 & $0.82(0.62-1.10)$ & 0.186 \\
\hline 2 & rs266729 & $C: G$ & 0.239 & 0.283 & $1.40(1.11-1.77)$ & $0.0044^{\star}$ \\
\hline 3 & $-10677 \mathrm{C}>\mathrm{T}^{\mathrm{a}}$ & C:T & 0.064 & 0.070 & $1.10(0.73-1.66)$ & 0.660 \\
\hline 4 & rs182052 & G:A & 0.407 & 0.428 & $1.17(0.94-1.44)$ & 0.162 \\
\hline 5 & rs16861205 & $G: A$ & 0.161 & 0.144 & $0.83(0.62-1.11)$ & 0.200 \\
\hline 6 & rs822395 & $A: C$ & 0.151 & 0.151 & $0.85(0.63-1.16)$ & 0.300 \\
\hline 7 & rs822396 & $A: G$ & 0.133 & 0.125 & $0.78(0.56-1.08)$ & 0.140 \\
\hline 8 & rs12495941 & G:T & 0.419 & 0.412 & $1.01(0.82-1.25)$ & 0.903 \\
\hline 9 & rs2241766 & $\mathrm{T}: \mathrm{G}$ & 0.298 & 0.288 & $0.99(0.79-1.24)$ & 0.933 \\
\hline 10 & rs1501299 & G:T & 0.260 & 0.275 & $1.06(0.85-1.33)$ & 0.613 \\
\hline 11 & rs3774262 & $\mathrm{G}: \mathrm{A}$ & 0.301 & 0.290 & $1.00(0.80-1.25)$ & 0.989 \\
\hline 12 & rs6773957 & $A: G$ & 0.441 & 0.439 & $0.97(0.79-1.20)$ & 0.778 \\
\hline 13 & rs1063539 & $\mathrm{G}: \mathrm{C}$ & 0.296 & 0.291 & $1.02(0.81-1.28)$ & 0.875 \\
\hline 14 & rs12629945 & G:A & 0.184 & 0.173 & $0.99(0.75-1.30)$ & 0.933 \\
\hline
\end{tabular}

$\mathrm{HT}$, hypertension; NT, normotension. All OR and $P$ values were adjusted for age and sex. ${ }^{\star} P$ values that can pass multiple testing correction $(P<0.0057)$. ${ }^{a}$ No rs number is assigned for this SNP.

2-h post-OGTT glucose, and lower HOMA-IR are independent factors associated with higher adiponectin level, explaining $31.3 \%$ variation in adiponectin level (Table 4). Sex-specific analysis showed similar results (data not shown). Therefore, in all subsequent analysis of adiponectin level, all models were adjusted for age, sex, BMI, triglycerides, HDL cholesterol, 2-h post-OGTT glucose, and HOMA-IR.

Several genetic variants were significantly associated with adiponectin level after adjusting for covariates (Fig. 1A). The minor alleles of SNPs 2 and 4 were significantly associated with lower level $(\beta=-0.067$, $P=0.0037$ and $\beta=-0.097, P<0.0001$ respectively), whereas the minor alleles of SNPs 3 and 8 were significantly associated with higher level $(\beta=0.069$, $P=0.0027$ and $\beta=0.103, P<0.0001$ respectively). None of the SNPs showed significant sex interaction $(P>0.05)$. Figure 1B shows the unadjusted geometric mean $(95 \% \mathrm{CI})$ of adiponectin level stratified by the genotypes of these four SNPs in men and women.

Table 3 Stepwise multiple logistic regression for hypertension in the subcohort of 1616 subjects. Age, sex, body mass index (BMI), triglycerides (In-transformed), high-density lipoprotein cholesterol, 2-h post-oral glucose tolerance test glucose (In-transformed), homeostasis model assessment of insulin resistance index (HOMA-IR) (In-transformed), high-sensitivity C-reactive protein (In-transformed), and single-nucleotide polymorphism 2 (SNP 2) were allowed to enter into the stepwise model.

\begin{tabular}{llr}
\hline Parameters & OR $(95 \% \mathrm{Cl})$ & \multicolumn{1}{c}{$\boldsymbol{P}$} \\
\hline Age (years) & $1.14(1.12-1.16)$ & $<0.001$ \\
BMI $\left(\mathrm{kg} / \mathrm{m}^{2}\right)$ & $1.19(1.12-1.25)$ & $<0.001$ \\
Triglycerides (mmol/l) & $1.56(1.07-2.28)$ & 0.021 \\
$\quad($ In-transformed) & & \\
HOMA-IR (In-transformed) & $2.14(1.51-3.04)$ & $<0.001$ \\
SNP 2 (rs266729) & $1.46(1.11-1.92)$ & 0.006 \\
Nagelkerke $r^{2}$ & 0.444 & \\
\hline
\end{tabular}

\section{Haplotype analysis}

Haplotypes were constructed using the SNPs 2, 3, 4, and 8 as these SNPs showed significant association with adiponectin level. There were four common haplotypes with frequency $>5 \%$, namely, CCGT $(36.2 \%)$, GCAG (24.1\%), CCAG (16.2\%), and CCGG (16.1\%).

Haplotype analysis revealed significant associations with both adiponectin level and hypertension (global $P<0.001$ and 0.01 respectively after adjusting for covariates). However, the overall haplotype association with adiponectin level became nonsignificant after controlling for the SNPs $4 \quad(P=0.085)$ or 8 $(P=0.217)$ alone, but not SNPs $2(P=0.0007)$ or 3 $(P=0.0007)$, suggesting that the significant haplotype association was mainly contributed by SNPs 4 and 8 . Similarly, the overall haplotype association with hypertension became nonsignificant after controlling for the SNP $2(P=0.124)$ alone, but not SNPs 3 $(P=0.011), 4(P=0.005)$, or $8(P=0.004)$, suggesting that the significant haplotype association was mainly contributed by SNP 2 .

\section{Discussion}

In this study, we showed that four genetic variants, namely rs266729 $(-11377 \mathrm{C}>\mathrm{G}), \quad-10677 \mathrm{C}>\mathrm{T}$, rs182052 (-10066G $>A)$, and rs12495941 $(-2668 \mathrm{G}>\mathrm{T})$ were associated with adiponectin level, with the effect being stronger for rs182052 and rs12495941. Among these SNPs, rs266729 and $-10677 \mathrm{C}>\mathrm{T}$ are located in the gene promoter region, whereas rs182052 and rs12495941 are located in the intron 1 region. When compared with other previous studies, there seems to be ethnic difference in the associations of genetic variants with adiponectin level. For example, in the Genetic Epidemiology of Metabolic 
Table 4 Stepwise multiple linear regression for adiponectin leve (In-transformed). Age, sex, body mass index (BMI), systolic blood pressure, mean arterial pressure, triglycerides (In-transformed), high-density lipoprotein (HDL) cholesterol, 2-h post-oral glucose tolerance test (OGTT) glucose (In-transformed), homeostasis mode assessment of insulin resistance index (HOMA-IR) (In-transformed), and high-sensitivity C-reactive protein (In-transformed) were allowed to enter into the stepwise model.

\begin{tabular}{lrr}
\hline Parameters & \multicolumn{1}{c}{$\boldsymbol{\beta}$} & \multicolumn{1}{c}{$\boldsymbol{P}$} \\
\hline Age (years) & 0.213 & $<0.001$ \\
Female gender & 0.154 & $<0.001$ \\
BMI $\left(\mathrm{kg} / \mathrm{m}^{2}\right.$ ) & -0.091 & 0.001 \\
Triglycerides (mmol/l) (In-transformed) & -0.098 & $<0.001$ \\
HDL cholesterol (mmol/l) & 0.234 & $<0.001$ \\
2-h post-OGTT glucose (mmol/l) & -0.098 & $<0.001$ \\
$\quad$ (In-transformed) & -0.140 & $<0.001$ \\
HOMA-IR (In-transformed) & 0.313 & \\
$R^{2}$ & & \\
\hline
\end{tabular}

Syndrome Study, SNPs rs3774261 (712A $>$ G) and rs6773957 (which were almost in complete LD) were the most strongly associated SNPs in ADIPOQ gene in Northern and Western European populations (11). In both the Insulin Resistance and Atherosclerosis Study Family Study and the Framingham Offspring Study (9, $12)$, the most strongly associated SNP was rs 1700539 $(-11391 G>A)$, which was not found in our population (18).

Based on the Alibaba2.1 program (26), the SNP rs12495941 is not involved in any putative transcription binding site, whereas the presence of the minor allele of the SNP rs182052 results in a loss of a Sp1binding site and gain of a CCAAT/enhancer-binding protein (C/EBP) $\beta$-binding site. Both binding sites are involved in adipocyte differentiation $(27,28)$. It has been shown that the first intron of the human $A D I P O Q$ gene contains a gene expression enhancer element, which responds to $\mathrm{C} / \mathrm{EBP} \alpha$, but not to $\mathrm{C} / \mathrm{EBP} \beta$ (29). It is interesting to investigate whether this enhancer element could also respond to Sp1.

Previous association studies on hypertension produced inconsistent results, likely due to a small contribution of individual genes, inadequate power for multiple testing, and confounding by environmental factors. In this study, we included only subjects who were persistently hypertensive or normotensive for the entire 6.4-year follow-up period. This could help to minimize the confounding effect of environmental factors and phenotype misclassification, and hence improve our power. In this way, our study is crosssectional, and may not establish the causal relationship between genetic variants in the $A D I P O Q$ gene and hypertension. However, given that we have shown previously in a subcohort of the CRISPS study that hypoadiponectinemia is a predictor of hypertension at year 5 (7) and genotypes are randomly assigned at conception, the finding of the SNP rs266729, associated with both adiponectin level and hypertension, may provide further supporting evidence for a role of adiponectin in the development of hypertension. This SNP showed a difference in MAF of about $4.4 \%$ between hypertensive and normotensive subjects, and a difference in diastolic blood pressure of about $1.3 \mathrm{mmHg}$ between subjects with CC and GG genotypes. Such small effect size is consistent with the findings from recent genome-wide association studies $(30,31)$. Nevertheless, our findings will need to be confirmed by an independent larger prospective cohort with a better power to detect associations with smaller effect size.

We and others have previously reported that the SNP rs2241766 $(45 \mathrm{~T}>\mathrm{G})$ was associated with or predicts the development of diabetes or hyperglycemic status $(18,32)$. Although dysglycemia and raised blood pressure coexist in a large proportion of subjects in our local population (17), it was rs266729, rather than rs2241766, that was associated with hypertension. Interestingly, rs266729 has been reported to be
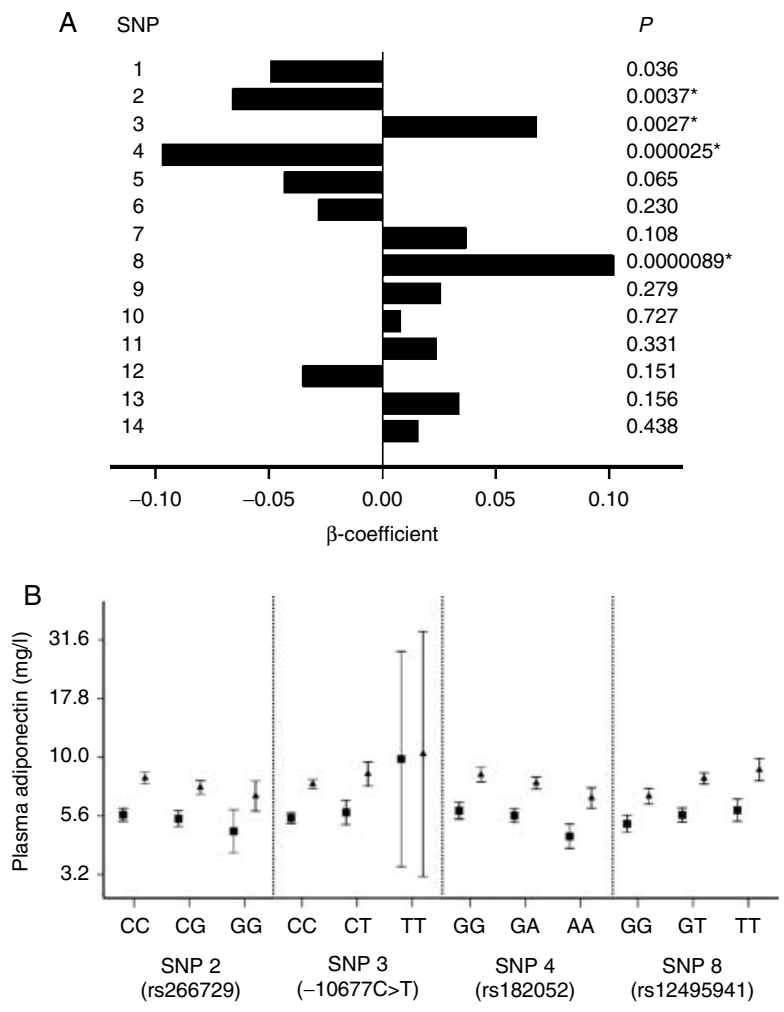

Figure 1 Associations of SNPs with adiponectin level. (A) The bar shows the magnitude of $\beta$-coefficients in multiple linear regression analysis of adiponectin level (In-transformed) after adjusting for age, sex, BMI, triglycerides (In-transformed), HDL cholesterol, 2-h post-OGTT glucose (In-transformed), and HOMA-IR (In-transformed). ${ }^{\star} P$ values that can pass multiple testing correction $(P<0.0057)$. (B) Unadjusted geometric mean of plasma adiponectin level stratified by different genotypes of the four SNPs that showed significant association with plasma adiponectin. The error bar shows the $95 \% \mathrm{Cl}$ of the geometric mean. Men and women are represented by a square and a triangle respectively. 
associated with diabetes, severe forms of obesity, carotid intima media thinkness, and other cardiovascular risks (33-37). This SNP was associated with adiponectin level in Caucasians $(10,33,38)$ and also with diabetic nephropathy in female type 1 diabetic patients, with the presence of the minor $G$ allele shown to destroy the binding site of transcriptional stimulatory protein, Sp1 (39). In a recent study, the minor allele of this SNP showed altered DNA-binding activity, leading to lower basal and inducible promoter activity in mouse 3T3-L1 adipocytes (40).

A recent study has demonstrated the significant genetic correlation of plasma adiponectin with HDL cholesterol and fasting insulin (41), in keeping with the well-known close association of hypoadiponectinemia with insulin resistance (1), an established risk factor for hypertension. Hypoadiponectinemia may also cause hypertension through several potential mechanisms such as insulin resistance, sympathetic activation, increased circulating fatty acid levels via reduced fatty acid oxidation, impaired endothelium-dependent vasodilation, and vascular inflammation (7). Although hypertension was associated with lower adiponectin level (5-7), there were few studies on the association of genetic variants with hypertension, which were all in Asians. One study in Taiwan only genotyped the SNP rs2241766 $(45 \mathrm{~T}>\mathrm{G})$ and reported no significant association with hypertension (6). Another Chinese study only genotyped the SNPs rs2241766 (45T>G) and rs1501299 (276G>T), and reported no significant association with hypertension (14). In a Japanese study which examined two SNPs in male subjects, a rare genetic variant, I164T (with MAF of $1.5 \%$ in hypertensive subjects and $0.2 \%$ in normotensive subjects), has been shown to be associated with lower adiponectin level and higher odds of hypertension (5). Although rare mutation in key regulatory pathway can often give rise to extreme phenotypes, it is unlikely to be the cause of common multifactorial diseases like hypertension in the general population (42).

In conclusion, several genetic variants in the $A D I P O Q$ gene were associated with adiponectin level in this Chinese population and among these variants, the SNP rs266729 was associated with hypertension among subjects who were persistently hypertensive or normotensive during a 6.4-year follow-up period. No significant sex interaction was found between genetic variants and adiponectin level or hypertension. Taken together with previous reports on hypoadiponectinemia in the prediction of hypertension $(7,8)$, our study has provided further evidence for a role of adiponectin in the development of hypertension.

\section{Declaration of interest}

The authors declare that there is no conflict of interest that could be perceived as prejudicing the impartiality of the research reported.

\section{Funding}

This study was funded by Hong Kong Research Grant Council grants (HKU7229/01M and HKU7626/07M), and the Sun Chieh Yeh Heart Foundation.

\section{References}

1 Weyer C, Funahashi T, Tanaka S, Hotta K, Matsuzawa Y, Pratley RE \& Tataranni PA. Hypoadiponectinemia in obesity and type 2 diabetes: close association with insulin resistance and hyperinsulinemia. Journal of Clinical Endocrinology and Metabolism 200186 1930-19305.

2 Berg AH, Combs TP \& Scherer PE. ACRP30/adiponectin: an adipokine regulating glucose and lipid metabolism. Trends in Endocrinology and Metabolism 200213 84-89.

3 Tan KC, Xu A, Chow WS, Lam MC, Ai VH, Tam SC \& Lam KS. Hypoadiponectinemia is associated with impaired endotheliumdependent vasodilation. Journal of Clinical Endocrinology and Metabolism 200489 765-769.

4 Zhu W, Cheng KK, Vanhoutte PM, Lam KS \& Xu A. Vascular effects of adiponectin: molecular mechanisms and potential therapeutic intervention. Clinical Science $2008114361-374$.

5 Iwashima Y, Katsuya T, Ishikawa K, Ouchi N, Ohishi M, Sugimoto K, Fu Y, Motone M, Yamamoto K, Matsuo A, Ohashi K, Kihara S, Funahashi T, Rakugi H, Matsuzawa Y \& Ogihara T. Hypoadiponectinemia is an independent risk factor for hypertension. Hypertension 200443 1318-1323.

6 Jeng JR. Plasma adiponectin, T94G gene polymorphism and PAI-1 in patients with and without hypertension. Cardiology $2007 \mathbf{1 0 7}$ 30-37.

7 Chow WS, Cheung BM, Tso AW, Xu A, Wat NM, Fong CH, Ong LH, Tam S, Tan KC, Janus ED, Lam TH \& Lam KS. Hypoadiponectinemia as a predictor for the development of hypertension: a 5-year prospective study. Hypertension $2007 \mathbf{4 9} 1455-1461$.

8 Imatoh T, Miyazaki M, Momose Y, Tanihara S \& Une H. Adiponectin levels associated with the development of hypertension: a prospective study. Hypertension Research $2008 \mathbf{3 1}$ 229-233.

9 Guo X, Saad MF, Langefeld CD, Williams AH, Cui J, Taylor KD, Norris JM, Jinagouda S, Darwin CH, Mitchell BD, Bergman RN, Sutton B, Chen YD, Wagenknecht LE, Bowden DW \& Rotter JI. Genome-wide linkage of plasma adiponectin reveals a major locus on chromosome $3 \mathrm{q}$ distinct from the adiponectin structural gene: the IRAS family study. Diabetes 200655 1723-1730.

10 Heid IM, Wagner SA, Gohlke H, Iglseder B, Mueller JC, Cip P, Ladurner G, Reiter R, Stadlmayr A, Mackevics V, Illig T, Kronenberg F \& Paulweber B. Genetic architecture of the APM1 gene and its influence on adiponectin plasma levels and parameters of the metabolic syndrome in 1,727 healthy Caucasians. Diabetes 200655 375-384.

11 Ling H, Waterworth DM, Stirnadel HA, Pollin TI, Barter PJ, Kesäniemi YA, Mahley RW, McPherson R, Waeber G, Bersot TP, Cohen JC, Grundy SM, Mooser VE \& Mitchell BD. Genome-wide linkage and association analyses to identify genes influencing adiponectin levels: the GEMS Study. Obesity 200917 737-744.

12 Hivert MF, Manning AK, McAteer JB, Florez JC, Dupuis J, Fox CS, O'Donnell CJ, Cupples LA \& Meigs JB. Common variants in the adiponectin gene (ADIPOQ) associated with plasma adiponectin levels, type 2 diabetes, and diabetes-related quantitative traits: the Framingham Offspring Study. Diabetes $2008 \mathbf{5 7}$ 3353-3359.

13 Chuang LM, Chiu YF, Sheu WH, Hung YJ, Ho LT, Grove J, Rodriguez B, Quertermous T, Chen YD, Hsiung CA, Tai TY \& Stanford Asia-Pacific Program of Hypertension and Insulin Resistance Study Group. Biethnic comparisons of autosomal genomic scan for loci linked to plasma adiponectin in populations of Chinese and Japanese origin. Journal of Clinical Endocrinology and Metabolism $2004 \mathbf{8 9} 5772-5778$. 
14 Yan WL, Chen SF, Huang JF, Shen Y, Qiang BQ, Liu DH \& Gu DF. Common SNPs of APM1 gene are not associated with hypertension or obesity in Chinese population. Biomedical and Environmental Sciences 200619 179-184.

15 Nishizawa H, Shimomura I, Kishida K, Maeda N, Kuriyama H, Nagaretani H, Matsuda M, Kondo H, Furuyama N, Kihara S, Nakamura T, Tochino Y, Funahashi T \& Matsuzawa Y. Androgens decrease plasma adiponectin, an insulin-sensitizing adipocytederived protein. Diabetes $2002512734-2741$.

16 Cheung BM, Wat NM, Man YB, Tam S, Thomas GN, Leung GM, Cheng $\mathrm{CH}$, Woo J, Janus ED, Lau CP, Lam TH \& Lam KS. Development of diabetes in Chinese with the metabolic syndrome: a 6-year prospective study. Diabetes Care 200730 1430-1436.

17 Cheung BM, Wat NM, Tso AW, Tam S, Thomas GN, Leung GM, Tse HF, Woo J, Janus ED, Lau CP, Lam TH \& Lam KS. Association between raised blood pressure and dysglycemia in Hong Kong Chinese. Diabetes Care 200831 1889-1891.

18 Tso AW, Sham PC, Wat NM, Xu A, Cheung BM, Rong R, Fong CH, $\mathrm{Xu}$ JY, Cheng KK, Janus ED \& Lam KS. Polymorphisms of the gene encoding adiponectin and glycaemic outcome of Chinese subjects with impaired glucose tolerance: a 5-year follow-up study. Diabetologia 200649 1806-1815.

$19 \mathrm{Xu} \mathrm{A}$, Chan KW, Hoo RL, Wang Y, Tan KC, Zhang J, Chen B, Lam MC, Tse C, Cooper GJ \& Lam KS. Testosterone selectively reduces the high molecular weight form of adiponectin by inhibiting its secretion from adipocytes. Journal of Biological Chemistry 2005280 18073-18080.

$20 \mathrm{Xu}$ A, Tso AW, Cheung BM, Wang Y, Wat NM, Fong CH, Yeung DC, Janus ED, Sham PC \& Lam KS. Circulating adipocyte-fatty acid binding protein levels predict the development of the metabolic syndrome: a 5-year prospective study. Circulation 2007115 1537-1543.

21 Lui MM, Lam JC, Mak HK, Xu A, Ooi C, Lam DC, Mak JC, Khong PL \& Ip MS. C-reactive protein is associated with obstructive sleep apnea independent of visceral obesity. Chest 2009135 950-956.

22 Barrett JC, Fry B, Maller J \& Daly MJ. Haploview: analysis and visualization of $\mathrm{LD}$ and haplotype maps. Bioinformatics 200521 263-265.

23 Purcell S, Neale B, Todd-Brown K, Thomas L, Ferreira MA, Bender D, Maller J, Sklar P, de Bakker PI, Daly MJ \& Sham PC. PLINK: a tool set for whole-genome association and populationbased linkage analyses. American Journal of Human Genetics 2007 81 559-575.

24 Nyholt DR. A simple correction for multiple testing for singlenucleotide polymorphisms in linkage disequilibrium with each other. American Journal of Human Genetics 2004 74 765-769.

25 Cui JS, Hopper JL \& Harrap SB. Antihypertensive treatments obscure familial contributions to blood pressure variation. Hypertension 200341 207-210.

26 Grabe N. AliBaba2: context specific identification of transcription factor binding sites. In Silico Biology 20022 S1-S15.

27 Barth N, Langmann T, Schölmerich J, Schmitz G \& Schäffler A. Identification of regulatory elements in the human adipose most abundant gene transcript-1 (apM-1) promoter: role of SP1/SP3 and TNF-alpha as regulatory pathways. Diabetologia $2002 \mathbf{4 5}$ 1425-1433.

28 Darlington GJ, Ross SE \& MacDougald OA. The role of C/EBP genes in adipocyte differentiation. Journal of Biological Chemistry 1998 273 30057-30060.

29 Qiao L, Maclean PS, Schaack J, Orlicky DJ, Darimont C, Pagliassotti M, Friedman JE \& Shao J. C/EBPalpha regulates human adiponectin gene transcription through an intronic enhancer. Diabetes $2005 \mathbf{5 4} 1744-1754$.

30 O'Shaughnessy KM. Dissecting complex traits: recent advances in hypertension genomics. Genome Medicine 2009143.
31 Delles C, McBride MW, Graham D, Padmanabhan S \& Dominiczak AF. Genetics of hypertension: from experimental animals to humans. Biochimica et Biophysica Acta, 2010. DOI: 10.1016/j.bbadis.2009.12.006.

32 Gable DR, Hurel SJ \& Humphries SE. Adiponectin and its gene variants as risk factors for insulin resistance, the metabolic syndrome and cardiovascular disease. Atherosclerosis $2006 \mathbf{1 8 8}$ 231-244.

33 Vasseur F, Helbecque N, Dina C, Lobbens S, Delannoy V, Gaget S, Boutin P, Vaxillaire M, Leprêtre F, Dupont S, Hara K, Clément K, Bihain B, Kadowaki T \& Froguel P. Single-nucleotide polymorphism haplotypes in the both proximal promoter and exon 3 of the APM1 gene modulate adipocyte-secreted adiponectin hormone levels and contribute to the genetic risk for type 2 diabetes in French Caucasians. Human Molecular Genetics 200211 2607-2614.

$34 \mathrm{Gu} \mathrm{HF}$, Abulaiti A, Ostenson CG, Humphreys K, Wahlestedt C, Brookes AJ \& Efendic S. Single nucleotide polymorphisms in the proximal promoter region of the adiponectin (APM1) gene are associated with type 2 diabetes in Swedish caucasians. Diabetes 200453 S31-S35.

35 Bouatia-Naji N, Meyre D, Lobbens S, Séron K, Fumeron F, Balkau B, Heude B, Jouret B, Scherer PE, Dina C, Weill J \& Froguel P. ACDC/adiponectin polymorphisms are associated with severe childhood and adult obesity. Diabetes 200655 545-550.

36 Hoefle G, Muendlein A, Saely CH, Risch L, Rein P, Koch L, Schmid F, Aczel S, Marte T, Langer P \& Drexel H. The -11377 C > G promoter variant of the adiponectin gene, prevalence of coronary atherosclerosis, and incidence of vascular events in men. Thrombosis and Haemostasis 200797 451-457.

37 Patel S, Flyvbjerg A, Kozàkovà M, Frystyk J, Ibrahim IM, Petrie JR, Avery PJ, Ferrannini E, Walker M \& RISC Investigators. Variation in the ADIPOQ gene promoter is associated with carotid intima media thickness independent of plasma adiponectin levels in healthy subjects. European Heart Journal 200829 386-393.

38 Vasseur F, Helbecque N, Lobbens S, Vasseur-Delannoy V, Dina C, Clément K, Boutin P, Kadowaki T, Scherer PE \& Froguel P. Hypoadiponectinaemia and high risk of type 2 diabetes are associated with adiponectin-encoding (ACDC) gene promoter variants in morbid obesity: evidence for a role of ACDC in diabesity. Diabetologia $2005 \mathbf{4 8} 892-899$.

39 Zhang D, Ma J, Brismar K, Efendic S \& Gu HF. A single nucleotide polymorphism alters the sequence of SP1 binding site in the adiponectin promoter region and is associated with diabetic nephropathy among type 1 diabetic patients in the Genetics of Kidneys in Diabetes Study. Journal of Diabetes and its Complications $200923265-272$.

40 Laumen H, Saningong AD, Heid IM, Hess J, Herder C, Claussnitzer M, Baumert J, Lamina C, Rathmann W, Sedlmeier EM, Klopp N, Thorand B, Wichmann HE, Illig T \& Hauner H. Functional characterization of promoter variants of the adiponectin gene complemented by epidemiological data. Diabetes 200958 984-991.

41 Henneman P, Aulchenko YS, Frants RR, Zorkoltseva IV, Zillikens MC, Frolich M, Oostra BA, van Dijk KW \& van Duijn CM. Genetic architecture of plasma adiponectin overlaps with the genetics of metabolic syndrome-related traits. Diabetes Care 201033 908-913.

42 Pritchard JK \& Cox NJ. The allelic architecture of human disease genes: common disease-common variant...or not? Human Molecular Genetics 200211 2417-2423.

Received 18 May 2010

Accepted 1 June 2010 